\title{
Introduction to the Smart Service Systems: Analytics, Cognition and Innovation Minitrack
}

\author{
Haluk Demirkan \\ U. of Washington-Tacoma \\ haluk@uw.edu
}

\author{
James C. Spohrer \\ IBM Almaden Research Center \\ spohrer@us.ibm.com
}

Ralph Badinelli
Virginia Tech
ralphb@,vt.edu
Economic and societal well-being depend on innovations that help people use big data more intelligently. Human-centered smart service systems for business and society can be characterized by: (1) the types of offerings to their customers and/or citizens, (2) the types of jobs or roles for people within them, and (3) the types of returns they offer investors interested in growth and development, through improved use of technology, talent, or organizational and governance forms, which create (dis)incentives that (re)shape behaviors. An important trend in smart service systems is the increasing availability of cognitive assistants (e.g., Siri, Watson, Jibo, Echo, Cortana, Bixby, Einstein, and Now) to boost productivity and creativity of all the people inside them.

Innovators of smart service systems, including entrepreneurs, managers, and policymakers seek to improve quality-of-service for customers, quality-of-life for citizens, and/or quality-of-returns for investors.

Smart service systems are ones that continuously improve (e.g., productivity, quality, compliance, sustainability, etc.) and co-evolve with all sectors (e.g., government, healthcare, education, finance, retail and hospitality, communication, energy, utilities, transportation, etc.). Regional service systems include nations, states, cities, universities, and hospitals. Global service systems include multi-national businesses, professional associations, and NGOs. Natural or human-made disasters, technology failures, criminal activities, political collapse can disrupt or negatively impact quality-oflife for people living and working in service systems.

Using big data analytics and cognitive systems to improve decision-making service providers try to compete for the hearts, minds, and wallets of collaborators by (1) improving existing offerings, (2) innovating new types of offerings, (3) evolving their portfolio of offerings, and, (4) changing their relationships to others in the ecosystem in ways stakeholders perceive as more positive, sustainable, fair, or responsible.

The goal of this mini track is to explore the challenges, issues and opportunities related to innovation of smart service systems that enable value co-creation with analytics, cognitive and human systems. This is the fourth time that we are offering this minitrack since 2015. The three papers accepted for the minitrack investigate these issues in different ways.
The first paper, titled "Service-Oriented Cognitive Analytics for Smart Service Systems: A Research Agenda" by Robin Hirt, Niklas Kühl, Björn Schmitz, Gerhard Satzger, proposes a research agenda for the development of a service-oriented cognitive analytic framework. The analytics framework uses a centralized cognitive aggregation model to combine predictions being made by each entity of the service system. Having introduced the architecture and the aggregation function of the framework, the authors propose a research design to develop and evaluate the service oriented cognitive analytics framework in future research.

"Service Dominant Architecture: Conceptualizing the Foundation for Execution of Digital Strategies based on S-D logic" by Peter Weiß, Andreas Zolnowski, Markus Warg, Thomas Schuster, reviews the challenges and opportunities for digital business models transformation, and propose that service dominant logic and service science provide a roadmap for sustainable digital strategies, because digitalization requires to focus on the customers' needs and to develop customer-centric solutions. Service Dominant Architecture encapsulates required enterprise capabilities in its subsystems and core components. They validate their framework with a set of case studies.

In the last paper titled "People's Interactions with Cognitive Assistants for Enhanced Performances" by Md. Abul Kalam Siddike, Jim Spohrer, Haluk Demirkan, Youji Kohda, reviews the understanding of people's interactions with smart machines, and develops a framework to boost people's performance through the interaction with cognitive assistants. According to the analysis that they performed, people's successful interaction with CAs enhances people's cognition, intelligence, and capabilities that help them to boost up their performance in their work. When cognitive computing enabled smart computers are growing in our daily lives, there are not many studies that explain how people interact and utilize these solutions, and the impact of these smart machines to people's performance to do things.

We hope you enjoy the papers and their presentation at the conference. We thank the authors for submitting their work to make this another engaging minitrack. We also thank the reviewers for their valuable feedback.

\section{Hî́CSS}

